\title{
Synthesis and Characterization of Silver Nanoparticles by Sol-Gel Technique
}

\author{
Mohammad Shahjahan, ", Md Hasibur Rahman², Mohammad Sajjad Hossain ${ }^{1}$, \\ Most Afroza Khatun ${ }^{2}$, Aminul Islam ${ }^{3}$, Most Hosney Ara Begum ${ }^{1}$ \\ ${ }^{1}$ Industrial Physics Division, BCSIR Laboratories Dhaka, Bangladesh Council of Scientific \& Industrial Research (BCSIR), Dhaka, \\ Bangladesh \\ ${ }^{2}$ Fibre \& Polymer Reserch Division, BCSIR Laboratories Dhaka, Bangladesh Council of Scientific \& Industrial Research (BCSIR), Dhaka, \\ Bangladesh \\ ${ }^{3}$ Jessore University of Science and Technology, Jessore, Bangladesh
}

\author{
Email address: \\ shahjahanphysics@gmail.com (M. Shahjahan) \\ *Corresponding author
}

\section{To cite this article:}

Mohammad Shahjahan, Md Hasibur Rahman, Mohammad Sajjad Hossain, Most Afroza Khatun, Aminul Islam, Most Hosney Ara Begum. Synthesis and Characterization of Silver Nanoparticles by Sol-Gel Technique. Nanoscience and Nanometrology.

Vol. 3, No. 1, 2017, pp. 34-39. doi: 10.11648/j.nsnm.20170301.16

Received: May 3, 2017; Accepted: May 25, 2017; Published: June 30, 2017

\begin{abstract}
In recent nanotechnology is the most promising field for the researchers. This paper describes a simple and convenient procedure for the preparation of crystalline silver nanoparticles. The aggregation of silver nanoparticles was prevented by $\mathrm{CH}_{3} \mathrm{COONa}$ in a chemical bath and then washed away, leaving crystalline silver nanoparticles. The silver nanoparticles were synthesized by sol-gel technique in the presence of $\mathrm{CH}_{3} \mathrm{COONa}$ and hydrazine as reducing agent in water at room temperature. The structure and grain size of prepared particles were characterized by Scanning Electron Microscope and X-ray Diffraction. The whole experiment has been carried out at room temperature, using water as solvent and also within very less time. From XRD pattern we got the crystallinity and the position of the crystal plane of the prepared particles was similar to the standard nano silver pattern and the average size of the particles was $11 \mathrm{~nm}$. For SEM study it was observed that the particles are homogenous and uniform size in the nano range cracked free surfaces with regular granular shaped grains without any impurities. There was no peak in the carbonyl frequency region confirmed that sodium acetate was not present within the silver particles. From STA study, we have observed that the weight loss was negligible assured the particles were pure. Hence we will describe an excellent scope for large scale production of silver nanocrystals which will have applications in electronics and catalysis.
\end{abstract}

Keywords: Silver Nanoparticles, XRD Technique, FT-IR Spectroscopy, Sol-Gel Technique, SEM Analysis

\section{Introduction}

Nanotechnology is the study, control and manipulation of materials at the nanoscales, typically having dimensions less than $100 \mathrm{~nm}$ [1]. Nanostructured materials have unique chemical and physical properties, but by their physical application in many fields have stimulated the search for a new synthetic method for material [2]. Metal nanoparticles have been enormously investigated because of their unique optoelectronic properties that are substantially different from bulk materials [3]. Nanoparticles are widely used as its size, orientation, physical properties; change the performance of material [4]. Finely dispersed nanostructures or nanoparticles are used in many medical and technological applications, e.g. ceramics and polymer composites, pigments, filler materials, electronics, catalysts and many others [5]. Also, its rapidly gaining importance in a number of areas such as healthcare, cosmetics, food and feed, environmental issue, optical device, biomedical application, chemical companies, electronics, drug delivery, energy, optoelectronics, catalysis, single electron transistors, light emitters, non-linear optical devices and photo-electrochemical applications [6]. It has 
been shown that the size, morphology, stability and properties (chemical and physical) of these nanoparticles much depend on the preparation technique and conditions they used in experiment [7]. The sol-gel has several advantages such as high purity, ultra- homogeneity, lowering the synthesis temperature and most significantly the possibility of making new compositions [8]. A technological revolution in the last decade is initiated by the invention of a new class of materials. Most of these materials, and the related devices made from them are in nanometer size (1-100 $\mathrm{nm}$ ) objects constituted of basic building blocks of metals, ceramics or polymers. Physical, chemical or biological methods may apply to control the properties of such materials that are novel and can be engineered in dimension.Silver nanoparticles have been drawn the attention of researchers because of their extensive applications in areas such as integrated circuits [9], sensors [9], bio-labelling, filters, antimicrobial deodorant fibers [10], cell electrodes [11], low cost paper, batteries [12] and antimicrobial [13] and extensively as antimicrobial agents in health industry, food storage, textile coatings and a number of environmental applications. The antimicrobial properties of it caused the use of these nano metals in different fields of medicine, various industries, animal husbandry, packaging, accessories, cosmetics, health and military [14]. Silver is well known for possessing an inhibitory effect toward many bacterial strains and micro-organism commonly presents in medical and industrial process [15]. In medicines, silver and silver nanoparticles have a huge application in skin ointments and creams to prevent infection of burns and open wounds [16]. Medical devices and implants prepared with silver impregnated polymers [17]. In the textile industry, silver embedded fabrics are now used in sporting equipment [18]. The most popular chemical approaches such as chemical reduction of organic and inorganic reducing agents, sol-gel techniques, electrochemical techniques, physic-chemical reduction and radiolysis are widely used in the synthesis silver nanoparticles. In order to prevent the aggregation of silver nanoparticles into clusters the protecting agents or stabilizers, which are amphiphilic, polymer polyvinyl pyrrolidone [19], poly vinyl alcohol [20], Sodium Dodecyl Sulfate or Citrate of Sodium [21], were used in the synthesis process. However, these additional agents can result in complex synthesis process, toxicity and higher cost. That's why for economical industrial applications the synthesis process without PVA, PVP, or SDS attracts attention. Silver is soft, white, transition metal it possesses the highest thermal and electrical conductivity, also reflectivity of any metal. Silver was of a particular interest in this process due to its evocative physical and chemical properties. The sol-gel process is a wet chemical technique widely used recently in the fields of materials in ceramic engineering. Such methods are used primarily for the fabrication of materials starting from a chemical solution, which act as the precursor for an integrated or discrete particle network (or gel) or network polymers. A versatile technique is presented for stabilizing $\mathrm{Ag}^{+}$ions in sol-gel systems. The particles were characterized by UV-vis spectroscopy and X-ray Diffractrometer, for observing the nucleation and growth of the metal nanoparticles [22]. A gel is a semi rigid mass that forms when the solvent form the sol begins to evaporate and the particle or ions left behind begins to join together in a continuous network.

Physical approaches use various metal NPs such as silver, gold, previously been synthesized using the evaporationcondensation method. The absence of solvent contamination in the prepared thin films and the uniformity of NPs distribution are the advantages of physical approaches in comparison with chemical processes. [23, 24]. Chemical approaches including chemical reduction using a variety of organic and inorganic reducing agents for the synthesis of silver NPs. Most of the methods are still in development stage and the experienced problems are the stability and aggregation of NPs, control of crystal growth, morphology, size and size distribution. Moreover extraction and purification of produced NPs are still important issues [25, 26, 27].

Our target is to synthesize silver nanoparticles of a clean surface. Here we report a simple and convenient sol gel technique for the synthesis of crystalline silver nanoparticles at room temperature. $\mathrm{N}_{2} \mathrm{H}_{4} \cdot \mathrm{H}_{2} \mathrm{O}$ has been used as reducing agent and Sodium acetate has been used as stabilizing agent for silver nanoparticles. The method produces crystalline silver nanoparticles free from stabilizing agent.

\section{Experimental Procedure}

\subsection{Materials and Method}

Analytical grade $\mathrm{AgNO}_{3}, \mathrm{CH}_{3} \mathrm{COOH}, \mathrm{NaOH}$ and $\mathrm{N}_{2} \mathrm{H}_{4} \cdot \mathrm{H}_{2} \mathrm{O}$ were used as raw materials for the preparation of Ag nanoparticle. The specified amount of metal nitrate and citric acid and sodium hydroxide solution was formed keeping the molar ratio of nitrates to citric acid 1:1. The $\mathrm{pH}$ value is adjusted at 7 using ammonia slowly to the solution. All glasswares were washed thoroughly and rinsed with distilled water. Silver nanoparticles were prepared by chemical reduction process using $\mathrm{N}_{2} \mathrm{H}_{4} \cdot \mathrm{H}_{2} \mathrm{O}$ as reducing catalyst. $100 \mathrm{ml}$ of $6 \mathrm{mM}, 7 \mathrm{mM}$, and $8 \mathrm{mM}$ aqueous solution of $\mathrm{AgNO}_{3}, 0.1 \mathrm{M}$ of citric acid, 0.1 Msodium hydroxide was added and stirred vigorously. In the above mixture solution $12 \mathrm{mM}, 16 \mathrm{mM}$ and $20 \mathrm{mM}$ of $\mathrm{N}_{2} \mathrm{H}_{4} \cdot \mathrm{H}_{2} \mathrm{O}$ was added respectively and stirred vigorously for making three different samples. The solution turned black after addition of $\mathrm{N}_{2} \mathrm{H}_{4} \cdot \mathrm{H}_{2} \mathrm{O}$ solution which confirms the silver ions was reduced. The solution was then stirred for 3 hours at room temperature.After that the solution was transparent and silver particles shining inside the flask. The particles werecollected using filter paper and then washed with deionized water and dried in air.

\subsection{Characterization}

The XRD of prepared silver nanopowder was recorded using BRUKER D8-XRD. The crystallinesize of the sample 
was calculated applying Scherrer's formula. Functional groups were analyzed by FTIR Spectrometer. The FTIR spectra were recorded in the range of $600 \mathrm{~cm}$ to $4000 \mathrm{~cm}$. The morphology of the prepared nano powder was shown by Scanning Electron Microscope.

\section{Results and Discussions}

\subsection{Structural Analysis}

The crystallinity of silver nanoparticles were determined from their XRD patterns. The figurel shows the XRD patterns of prepared Ag nanoparticles. As shown five peaks are recognizable at Bragg angles of 38.1, 44.2, 64.5, 77.34, and 81.38 respectively, corresponds to a lattice plane (111), (200), (220), (311) and (222) respectively. These peaks correspond to the reflection of the face centered cubic structure of metallic silver. Lattice constant and other structural parameters of the spin phase determination was made from the X-ray diffraction patterns. From literature we got the structural parameters and atomic positions for the spinel phase. The lattice constant "a" was calculated using the formula

$$
a=d_{h k l} \sqrt{h^{2}+k^{2}+l^{2}}
$$

Where $h, k, l$ are the Miller indices and $d_{h k l}$ is the inter planer spacing. The crystallite sizes of prepared powders were calculated by substituting the full width at half maximum (FWHM) and Bragg angles in Scherrer's formula:D $=0.94 \lambda \square \beta \cos \theta$

In which $\mathrm{D}$ corresponds to the mean crystallite in $\AA$, $\lambda=1.54 \AA$ in the $\mathrm{x}$-ray wavelength, $\beta$ corresponds to FWHM in radian and $\theta$ half diffraction angle. The broadening shows nanometer range of particles without an impurity phase. The more intense peak (111) is chosen to determine the crystallite size and lattice strain of the nanoparticles. The prominent peak present in the graph indicates excellent crystalinity of silver nanoparticles.

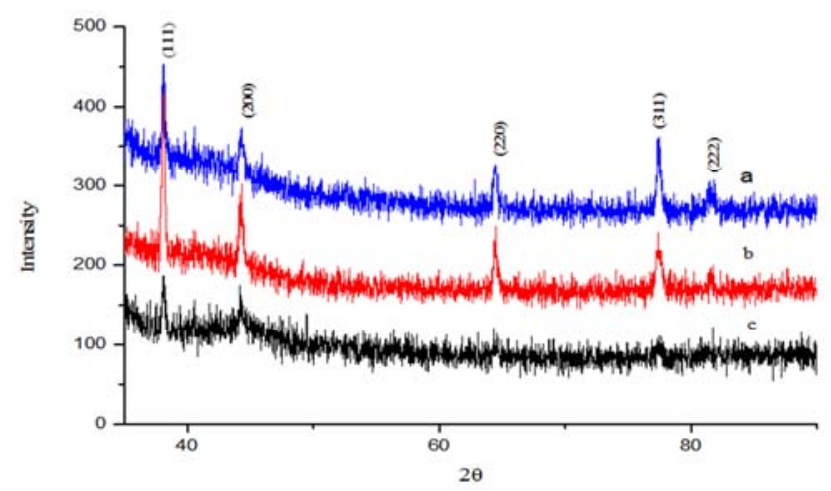

Figure 1. X-ray diffraction pattern for silver nanoparticles prepared from different concentration of silver salt: (a) $6 \mathrm{mM} \mathrm{AgNO} \times 12 \mathrm{mM} \mathrm{N}_{2} \mathrm{H}_{4} \cdot \mathrm{H}_{2} \mathrm{O}$ (b) $7 m M \mathrm{AgNO}_{3} \times 16 \mathrm{mM} \mathrm{N}_{2} \mathrm{H}_{4} \cdot \mathrm{H}_{2} \mathrm{O}$, (c) $8 \mathrm{mM} \mathrm{AgNO} \times 20 \mathrm{mM} \mathrm{N}_{2} \mathrm{H}_{4} \cdot \mathrm{H}_{2} \mathrm{O}$ showing peak intensities and $2 \theta$ positions.

The average crystallite sizes were calculated from X-ray line broadening of the (111) diffraction peak using Debye Scherrer's equation by considering the instrumental line broadening factor. The FCC crystal structure of silver lattice constant is ' $a$ ' $=4.08620 \AA$ and this value is calculated theoretically by using formula,

$$
\mathrm{a}=4 / \sqrt{ } 2 \times \mathrm{r}
$$

where $r$ is the radius of the silver atom. For silver $r=144 \mathrm{pm}$. The experimental lattice constant ' $a$ ' from the most intense peak (111) of the XRD pattern is $4.0885,4.0893$ and 4.0880 $\AA$ for all three samples. Both theoretical \& experimental lattice constant ' $a$ ' are in very good agreement for all samples. It is worth noting that the ratio between the intensities of the (200) \& (111) diffraction peaks and (220) \& (111) peaks is also slightly higher than the conventional value $(0.68$ versus 0.40$)$ and $(0.48$ versus 0.25$)$ for first sample 1 and very close for others sample. Some structural parameter is presented in table 1.

Table.1. The crystal size of Silver nanopowder.

\begin{tabular}{llll}
\hline Sample & Crystal size (nm) & Crystal strain & $\begin{array}{l}\text { Lattice constant in } \\
\text { angstrom }\end{array}$ \\
\hline 1 & 6.22 & 0.0178 & 4.0885 \\
2 & 19.19 & 0.0058 & 4.0893 \\
3 & 22.50 & 0.0049 & 4.0880 \\
\hline
\end{tabular}

Broadening Correction

The observed line broadening is used to estimate the average size of the particles. The sample and the instrument is responsible for the total broadening

The sample broadening is described by

$$
F W(S) \times \cos \theta=\frac{K \times \lambda}{\text { Size }}+4 \times \operatorname{Strain} \times \sin \theta
$$

The total broadening $\beta_{\mathrm{t}}$ is given by the equation

$$
\beta_{t}^{2} \approx\left\{\frac{0.9 \lambda}{D \cos \theta}\right\}^{2}+\{4 \varepsilon \tan \theta\}^{2}+\beta_{0}^{2}
$$

Where, $\varepsilon$ is strain and $\beta_{0}$ instrumental broadening. The average particle size D and the $\varepsilon$ strain of the experimentally observed broadening of several peaks will be computed simultaneously Here, Williamson-Hall plot is plotted with $\sin \theta$ on the $x$-axis and $\beta \cos \theta$ on the $y$-axis (in radians). A linear fit is got for the data. From this fit, we got particle size and strain from y-intercept and slope respectively [10]. The extracted particle size is $8 \mathrm{~nm}$ and strain is 0.004 for sample 1. Figure 2 shows Williamson Hall Plot.

Dislocation Density

The dislocation density $(\delta)$ in the sample has been determined using expression [17].

$$
\delta=\frac{15 \beta \cos \theta}{4 a D}
$$

where $\delta$ is dislocation density, $\beta$ is line broadening of diffraction measured at half of its maximum intensity (radian), $\theta$ is Bragg's diffraction angle (degree), $a$ is lattice constant $(\mathrm{nm})$ and $D$ is particle size $(\mathrm{nm})$. A dislocation is a 
crystallographic defect, or irregularity which strongly influences many of the properties of materials within a crystal structure. So it's a topological defect increases with plastic deformation. A mechanism for dislocation formation is formed with the help of grain boundary initiation, homogeneous nucleation, interfaces the lattice and the surface, precipitates, dispersed phases, or reinforcing fibers. Two dislocations present in the sample impeded movement of each other. Thus, a larger hardness is due to larger dislocation density. The average dislocation density of silver is $\sim 13.73 \pm 2 \times 10^{14} \mathrm{~m}^{-}$as obtained from the analysis of $\mathrm{X}$ ray line profiles [28]. The strength of materials increases with decreasing grain size wit in the limit of certain grain size limit ( 20 nm) [29, 30].

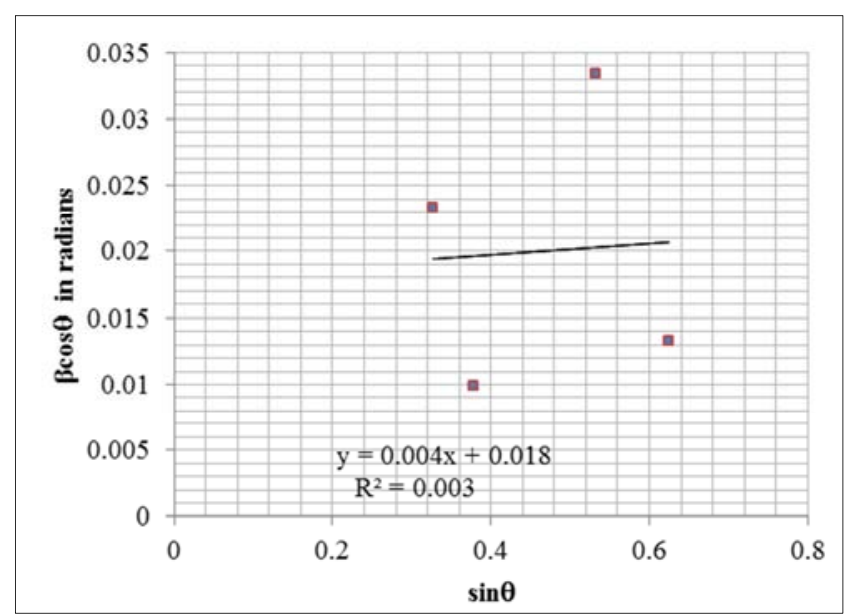

Figure 2. Williamson Hall Plot is indicating line broadening value due to the equipment.

\section{Specific Surface Area}

Specific surface area (SSA) has a particular importance in case of adsorption, heterogeneous catalysis and reactions on surfaces. SSA is the Surface Area (SA) per mass.

$$
S S A=\frac{S A_{\text {part }}}{V_{\text {part }}^{* \text { density }}}
$$

Here $\mathrm{V}_{\text {part }}$ is particle volume and $\mathrm{SA}_{\text {part }}$ is particle $\mathrm{SA}$ $\mathrm{S}=6 * 10^{3} / \mathrm{D}_{\mathrm{p}} \rho$

Where $\mathrm{S}$ is the specific surface area, $\mathrm{Dp}$ is the size of the particles, and $\rho$ is the density of silver $10.5 \mathrm{~g} / \mathrm{cm}^{3}$ [20]. SSA can be calculated from these formulas. Same result was obtained from both of the formula. The calculated value of SSA of the prepared silver nanoparticles is 91 $\mathrm{m}^{2} / \mathrm{g}$.

\subsection{Morphological Studies of Silver Nanoparticles}

Nanostructural studies and surface morphological are summarized in Figure3 using Scanning Electron Microscope (SEM). The results clearly indicate that silver nanoparticles are mono-dispersive and highly crystalline and the appearance is spherical in shape. The grain sizes of the samples obtained from the SEM picture are larger than that obtained from XRD data. This means that, the crystal we made is polycrystalline. Generally, on the nanometer scale, metals tend to nucleate and grow into twinned and multiply twinned particles (MTPs) with their surfaces bounded by the low-energy $\{111\}$ facets. Also, we observed image has some larger nanoparticles. This means Ag nanoparticles have the tendency to agglomerate due to their high surface energy and high surface tension. The finer particle size results in a large surface. Area enhances the nanoparticles catalytic activity.

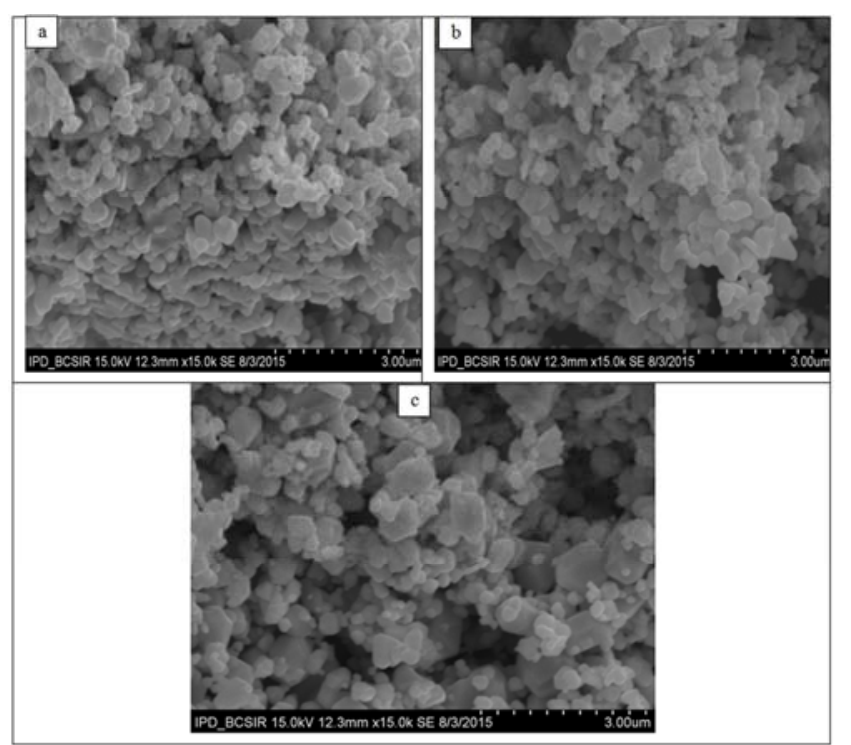

Figure 3. SEM pictures showing silver nanoparticles for all three samples:

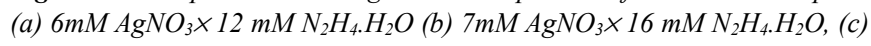
$8 \mathrm{mM} \mathrm{AgNO}_{3} \times 20 \mathrm{mM} \mathrm{N}_{2} \mathrm{H}_{4} \cdot \mathrm{H}_{2} \mathrm{O}$.

\subsection{FTIR Analyses Silver Nanoparticles}

In figure 4 FTIR spectra have been recorded to ensure the presence of acetate as an integral part of silver particles. IR spectra of sodium acetate show two peaks at $1560 \mathrm{~cm}^{-1}$ and $1413 \mathrm{~cm}^{-1}$ represent the stretching frequency of carbonyl. However, in the IR spectra of silver nanoparticles it was clearly observed that there was no peak in the carbonyl frequency region confirmed the absences of acetate with silver particles.

Again, we see from figure, there are four closely connected peaks at $2376.62 \mathrm{~cm}^{-1}, 2360.14 \mathrm{~cm}^{-1}, 2352.12 \mathrm{~cm}^{-}$ $1,2334.82 \mathrm{~cm}^{-1}$. All the peaks are represent that the presence of $-\mathrm{C}=\mathrm{N}$ - bond with silver nanoparticles. The intense peak at $2117 \mathrm{~cm}^{-1}$ represents the presence of $-\mathrm{C}-\mathrm{C}$ - with silver nanoparticles. Another intense peak at $1763 \mathrm{~cm}^{-1}$ to $1665 \mathrm{~cm}^{-}$ ${ }^{1}$ represent the $-\mathrm{C}-\mathrm{O}$ - with silver nanoparticles.

Again the experiment conducted without the addition of acetate led to the aggregation of particles to big particles of silver metal, instead of crystalline powders, confirms the role of acetate as stabilizing agent. In chemical bath, addition of reducing agent, hydrazine into the aqueous solution containing both silver and acetate ions leads to formation of small silver metallic particles. Due to ionization of acetate in water, there is an electrostatic repulsion between adjacent acetate ions that kept silver particles separated and prevents from aggregation. However the acetate is not bound to silver 
and ultimately washed away, leaving silver powders only. Unlike others stabilizing agents, here acetate does not remain an integral part of silver nanoparticles.

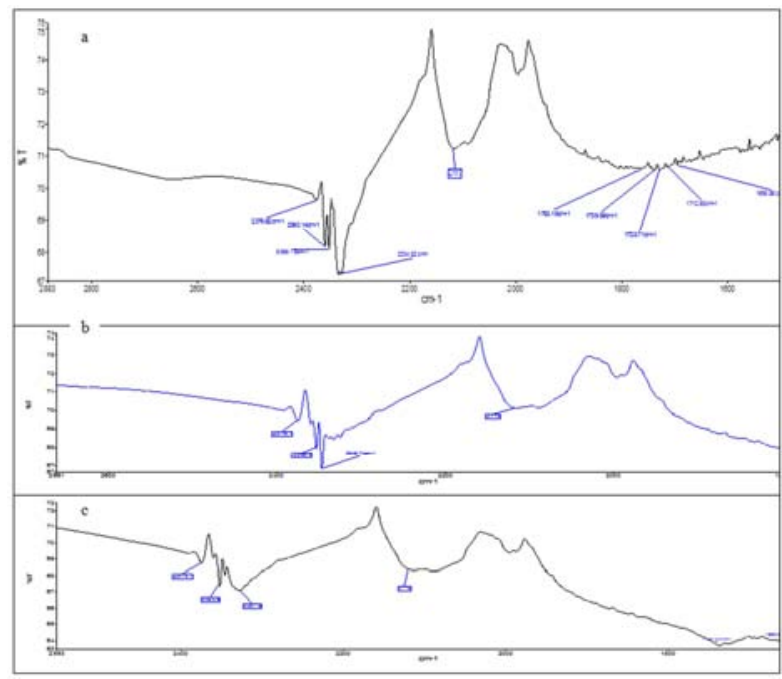

Figure 4. Wave number $\left(\mathrm{cm}^{-1}\right)$ of the dominant peaks obtained from FT-IR absorption spectra for all samples (a) $6 \mathrm{mM} \mathrm{AgNO} \mathrm{m}_{3} \times 12 \mathrm{mM} \mathrm{N} \mathrm{N}_{2} \mathrm{H}_{4} \cdot \mathrm{H}_{2} \mathrm{O}$ (b) $7 \mathrm{mM} \mathrm{AgNO}_{3} \times 16 \mathrm{mM} \mathrm{N}_{2} \mathrm{H}_{4} \cdot \mathrm{H}_{2} \mathrm{O}$, (c) $8 \mathrm{mM} \mathrm{AgNO} \mathrm{O}_{3} \times 20 \mathrm{mM} \mathrm{N}_{2} \mathrm{H}_{4} \cdot \mathrm{H}_{2} \mathrm{O}$.

\subsection{STA Analyses of Silver Nanoparticles}

In figure $5 \mathrm{TG}$ curves represent that the weight loss of the particles is negligible $(0.14 \%)$. So this confirms that the absence of acetate as an integral part of silver nanoparticles. So we said that the prepared powder was pure. Also the DSC curve represents that the powder was melted at $554.4 \mathrm{c}$ and the energy absorbed was $739.5 \mathrm{j} / \mathrm{g}$.

\section{Conclusion}

We have reported a simple, convenient and cost effective and environment friendly route to synthesize crystalline silver nanoparticles. This method was less time taking and reproducible. Also provides ecofriendly, clean, nontoxic and efficient route for the synthesis of nanoparticles with tunable particle size, at room temperature conditions without using any additive. We avoid to use high pressure, energy, temperature, toxic chemicals, downstream processing etc in every steps of synthesis. This technique finds an excellent scope for large scale production of silver nono crystals which will have applications in electronics and catalysis. The particle size of silver powders in the as-synthesized material were 6,19 and $22 \mathrm{~nm}$ and spherical. For the practical uses of wide variety of nanoparticles to practical use it is essential to establish technology for measuring and evaluating the characteristics and performance of nanoparticles and nanostructured. Their characterizations have been successfully done using XRD, SEM, STA and FTIR spectroscopic techniques. Ag nanoparticles were formed by low cost, easy and simple aqueous Chemical Bath Deposition (CBD) method using Sol-Gel Technique. We hope that we may prepare some other nano powder in future following this study. This may be useful in food industries, cosmetic industries, medicines and other industries.
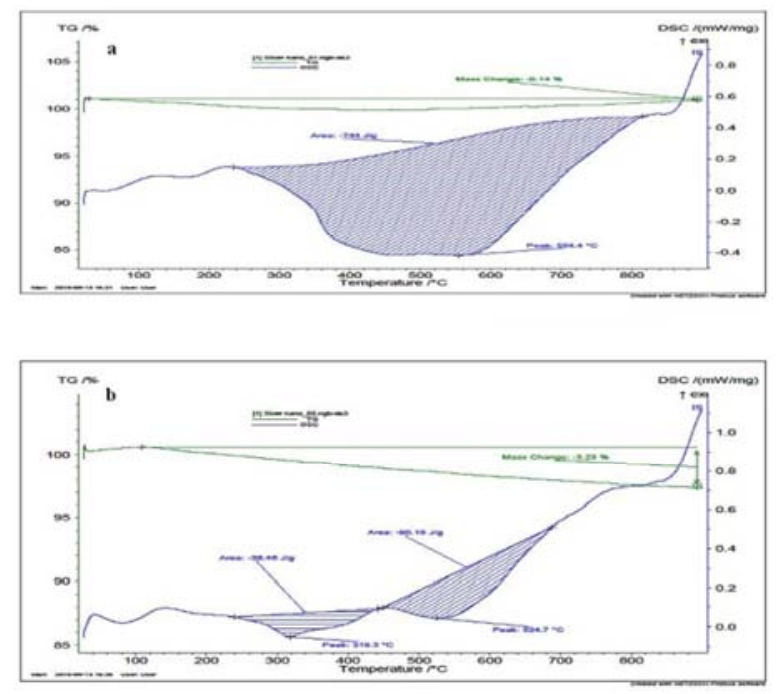

Figure 5. STA patterns of silver nanopartilces:(a) $6 \mathrm{mM} \mathrm{AgNO}_{3} \times 12 \mathrm{~mm}$ $\mathrm{N}_{2} \mathrm{H}_{4} \cdot \mathrm{H}_{2} \mathrm{O}$ (b) $7 \mathrm{~mm} \mathrm{AgNO}_{3} \times 16 \mathrm{mM} \mathrm{N}_{2} \mathrm{H}_{4} \cdot \mathrm{H}_{2} \mathrm{O}$.

\section{Acknowledgement}

We would like to express our grateful thanks and gratitude to the authority of BCSIR and Director, BCSIR Laboratories Dhaka for providing us the opportunity and necessary permission to carry out this research work. Thanks are also due to all the employees of Industrial Physics Division, BCSIR Laboratories, Dhaka.

\section{References}

[1] K. Mallikarjuna, G. R. Dillip, G. Narasimha, N. John Sushma, B. Deva Prasad Raju, "Phytofabrication and Characterization of Silver Nanoparticles from Piper betle Broth", Res. J. Nanosci. and Nanotech, 2, 17-23 (2012).

[2] M. A. Meyers, A. Mishra, D. J. Benson,"Mechanical properties of nanocrystalline materials", Prog. Mater sci., 51 (4), 427-556 (2006).

[3] G. Schimd, L. F. Chi. "Metal Clusters and Colloids," $A d v$. Mater., 10 (7), 515 (1998).

[4] M. C. Daniel, D. Astruc"Gold nanoparticles: assembly, supramolecular chemistry, quantum-size-related properties, and applications toward biology, catalysis, and nanotechnology". Chem Rev, 104 (1), 293-346 (2004).

[5] M. Willert, R. Rothe, K. Landfaster, M. Antonietti, "Synthesis of inorganic and metallic nanoparticles by miniemulsification of molten salts and metals",Chem. Mater.,13 (12), 4681-4685, (2001).

[6] V. Colvin, M. Schlamp, A. Alivisatos, "Light emitting diodes made from cadmium selenidenanocrystals and a semiconducting polymer.". Nature, 370, 354-357 (1994).

[7] N. Yanagihara, K. Uchida, M. Wakabayashi, Y. Uetake, T. Hara, "Effect of Radical Initiators on the Size and Formation of Silver Nanoclusters in Poly (methyl methycrylate)," Langmuir, 15 (9). 3038-3041, (1999). 
[8] H. J. Jeon, S. C. Yi, and S. G. Oh, "Preparation and antibacterial effects of $\mathrm{Ag}-\mathrm{SiO}_{2}$ thin films by sol-gel method", Biomaterials, 24 (27), 4921-4928, (2003).

[9] S. G. Kotthaus, B. H. Hang, R. H. Schafer, "Study of isotropically conductive bondings filled with aggregates of nano-sited Ag-particles". IEEE Trans Compon Packaging Technol, 20, 15-20 (1997).

[10] L. Zhao, H. Wang, K. Huo, L. Cui, W. Zhang, H. Ni, Y. Zhang, Z. Wu, P. K. Chu, "Antibacterial nano-structured titania coating incorporated with silvernanoparticles"Biomaterials, 32, 5706, (2011).

[11] T. Klaus-Joerger, R. Joerger, E.Olsson, C. G. Granqvist, "Bacteria as workers in the living factory: metal-accumulating bacteria and their potential for materials science". Trends in Biotechnology, 19 (1), 15-20 (2001).

[12] K. H. P. Hong, J. L. Park, I. H. Sul, J. H. Youk, T. J Kang, "Preparation of antimicrobial poly (vinyl alcohol) nanofibers containing silver nanoparticles".J PolymSci Part B PolymPhys, 2006. 44, 2468-2472 (2006).

[13] K. H. Cho, J-E Park. Cho, T. Osaka, S. G. Park, "The study of antimicrobial activity and preservative effects of nanosilver ingredient",ElectrochimicaActa, 51 (5) 956-960, (2005).

[14] N. Dura'n, P. D. Marcato, G. I. H. De Suoza, O. L. Alves, E. Esposito, "Antibacterial effect of silver nanoparticles produced by fungal process on textile fabrics and their effluent treatment."J Biomed Nanotechnol, 3, 203-208 (2007).

[15] H. Jiang, S. Manolache, A. C. L. Wong, F. S. Denes, "Plasma enhanced deposition of silver nanoparticles onto polymer and metal surfaces for the generation of antimicrobial characteristics",J Appl. PolyrSci. 93 (3), 1411-1422 (2004).

[16] N. Duran, P. D. Marcato, O. L. Alves, G. I. H. de Souza, E. Esposito, "Mechanistic aspects of biosynthesis of silver nano particles by several Fusariumoxyporum strains," $J$. Nanobiotechnology, 3, 8-14 (2005).

[17] R. O. Becker, "Silver ions in the treatment of local infections," Met based drugs, 6, 297-300 (1999).

[18] T. Klaus, R. Joerger, E. Olsson, E Olssan, C. G Granqvist,
"Silver based crystalline nanoparticles, microbially fabricated", Procnatlacad sci, 96 (24), 13611-13614 (1999).

[19] K. S. Chou, C. C. Chen, "Fabrication and characterization of silver core and porous silica shell nanocomposites particles", Micropor. Mesopor.Mat., 98, 208-213, (2007).

[20] A. A. El-kheshen, S. F. G. EL-Rab, "Effect of reducing and protecting agents on size of silver nanoparticles and their antibacterial activity", Der. Pharma. Chemica., 4 (1), 53-65, (2012).

[21] M. G. Guzman, J. Dille, S. Godet, "Synthesis of silver nanoparticles by chemical reduction method and their antibacterial activity", Int. J. Chem. Biomolecular Eng., 2-3, 104-111, (2009).

[22] M. Epifani, C. Giannini,L. Tapfer,L. Vasanelli, "Sol-Gel synthesis and characterization of $\mathrm{Ag}$ and $\mathrm{Au}$ nanoparticles in $\mathrm{SiO}_{2}, \mathrm{TiO}_{2}$ and $\mathrm{ZrO}_{2}$ thin films" Journal of the American ceramic society, 83 (10), 2385-2393, (2000).

[23] F. F H Kruis, \& B. Rellinghaus, B., "Sintering and evaporation characteristics of gas-phase synthesis of sizeselected PbS nanoparticles." Mater Sci Eng B, 2000. 69: p. 329-324.

[24] M. D. K Magnusson, J. Malm, J. Bovin, \& L. Samuelson, Gold nanoparticles: production, reshaping, and thermal charging.."J Nanoparticle Res, 1999. 1: p. 243-251.

[25] M. Sastry, A. Ahmad A, MI. Khan, R. Kumar. Biosynthesis of metal nanoparticles using fungi and actinomycete. Curr Sci. 2003; 85: 162-170.

[26] S. Iravani. Green synthesis of metal nanoparticles using plants. Green Chem. 2011; 13: 2638-2650.

[27] H. Korbekandi, S. Iravani S, S. Abbasi. Production of nanoparticles using organisms. Crit Rev Biotech. 2009; 29: 279-306.

[28] J. Gubicza, N. Q. Chinh, J. L. Labar, Z. Hegedus, P. Szommer, G. Tichy, T. G. Langdon, J. Mater.Sci. 43, 5672 (2008).

[29] J. R. Weertman, Mater. Sci. Eng. A. 166, 161 (1993).

[30] H. Van Swygenhoven, Science 296, 66 (2002). 